\title{
Curriculum as conversation
}

\author{
Alan Bleakley
}

Received: 26 May 2009/ Accepted: 26 May 2009/Published online: 12 June 2009

(C) Springer Science+Business Media B.V. 2009

In this edition of the journal you will find a stimulating set of articles concerned with deliberate curriculum interventions across the spectrum of the health professions. Most of these articles, explicitly or by implication, touch on issues of power. For example, McKenna et al. (2009) discuss ways of structuring midwifery students' work placements to provide for continuity of experience and early professional socialisation, thus directly empowering students as proto-professionals; while Delany and Watkin (2009) suggest ways of structuring post-placement reflection for physiotherapy students to gain critical insights into issues such as power effects in professional hierarchies, empowering apprentices as critics of the professional culture they will enter. Both of these articles show how power can be productive as well as repressive-productive of insights and knowledge that come to form professional identities.

Two articles describe how deliberate curriculum interventions in dental education (Kaiser et al. 2009) and medical education (Kumagai et al. 2009) can shape a patientcentred, rather than subject-centred, outlook: in dental education, to shift emphasis from the role of the dentist as technician (limited to diagnosis and clinical intervention) to public health educator (preventive dentistry); and in a medical specialty-diabetes - to shift from lecture and textbook learning, focused on clinical issues, to learning from patients' narratives. Here, a chronic patient's expertise in his or her own illness is taken seriously, as a resource. In both cases, the shift to a patient-centred outlook sounds the death knell of paternalism in medical and dental education (Coulter 2002).

These approaches also illustrate a wider change in health professions education discourse-where more horizontal power-sharing structures are replacing traditional, vertical hierarchies. Patients or clients are central figures in the new power-sharing (and powergenerating) structures. Where knowledge and power are intimately linked, expert patients, such as those with chronic illnesses, have personal knowledge from which clinicians can learn, then generating power for both the patient and clinician. Benbassatt and Baumal (2009) offer a critique of the traditional ways in which senior medical faculty exert

\footnotetext{
A. Bleakley $(\square)$

Peninsula Medical School, Peninsula College of Medicine and Dentistry, Institute of Clinical Education, Knowledge Spa, Royal Cornwall Hospital, Universities of Exerter and Plymouth, Truro, Cornwall TR1 3HD, UK

e-mail: alan.bleakley@pms.ac.uk
} 
authority over students through paternalistic models of teaching clinical skills, particularly where interviewing patients. The authors describe a more democratic, dialogue-based structure for the pedagogy of patient interviewing.

All of this adds up to the much-needed introduction of participative or constituent democracy in medical and health care education, an approach first introduced by John Dewey over a century ago. Where we demand democracy in our everyday lives, it is strange that autocracy has for so long been considered acceptable in education for the professions. At the heart of a democratic education practice is the use of constructive feedback. In two articles, we see how important it is to give deliberate and structured feedback as a curriculum intervention-whether to medical students as summative evaluations in ward learning settings (Hasley and Arnold 2009), or to physicians in multisource feedback contexts such as appraisals (Sargeant et al. 2009). Structuring feedback is particularly important. In the Hasley and Arnold (2009) study, where such feedback to students was only 'corrective', and not 'elaborated', it served little use in remediation. For Sargeant et al. (2009), feedback served to stimulate reflection by physicians, especially where such feedback appeared inconsistent with self perception. Importantly, however, feedback was of little use if it was not processed through reflection. This suggests that while structured feedback may stimulate reflection, structuring feedback serves little purpose if reflection is absent. Therefore, reflection should be taught, learned and assessed as a formal curriculum component (as it is on many health professions programmes). However, as Delany and Watkin (2009) point out, how the process of reflection itself is structured (in their case, as a 'critical' process unveiling power effects) is important.

Offering and structuring feedback already suggests participative democracy. Reflection deepens the process as it shapes a democratic identity in two ways. First, to introspectively sort through one's own values hierarchy and to ask: why do these values inform my practice rather than another set of values; and, how might I review, or relativise, guiding values in light of competing evidence or consideration of new views? This process is better termed critical 'reflexivity' (Finlay and Gough 2003). Second, reflection can work outwards, as a democratic intervention, through critical examination of power structures of the sort that Delany and Watkin (2009) describe, in order to challenge inequalities or inequities in such structures. How such reflection might work to challenge previously unexamined inequalities in the exercise of power in caregiving is explored by Hsieh et al. (2009), who describe how caregivers for the institutionalized elderly can engage in potentially psychologically abusive behaviour without recognising this. Implementing an educational support group can generate insights to defuse this potentially damaging power relationship.

Since Foucault's (2005) groundbreaking work analysing historical regimes of 'care of the self' and the hermeneutics of the subject, we are now more aware that power is not limited to 'sovereign' power exerted by others (power 'over'), nor to 'capillary' power produced as forms of resistance within a system (power 'through'), but is, paradoxically, exerted by self over self in regimes of discipline and control, as a way of constructing identity. Reflection on one's own values and performance, perhaps leading to 'self assessment', provides the classic example of such a self-regulating regime in contemporary education. Medical students are notoriously stressed by the intensity of the curriculum and are prone to suffer symptoms, especially at key points such as just before examinations. Hassed et al. (2009) describe how a structured curriculum intervention focusing upon 'self care skills' can serve to alleviate such stress. This is an example of paradoxical selfdisciplining, where power is directed inward and works in service of both control and production. 
However, apart from the paper by Delany and Watkin (2009), none of these authors explicitly open up discussions of the relationship between power, identity and curriculum structures, as if curriculum activity is a transparent technical process and not a discursive one, or is happening in a bubble, insulated from historical and cultural effects. By 'discourse' (Latin discursus - 'running to and from'), I mean humans engaging in socially, culturally and historically situated activities of conversation and practice to decide upon what is a legitimate activity in any field. What are the limits of such legitimacy? If discourse is a running back and forth — a dialogue, conversation and debate- 'curriculum' literally means 'running the race', where the Latin source-currere-describes running the chariot race or completing the course (in our case, a course of study). Our focus is not on who is running the race, or completing the course, but on how the course is set up in the first place. Who decides what and how the course of study shall be, and on what grounds? These are again issues of legitimacy and power, necessarily paradoxical.

For example, how does an evidence-based approach gain ascendancy, privilege, respectability and even legitimacy, over narrative-based medicine? This is easy to answer-because of the cultural dominance of the scientific discourse as a means of knowledge and truth production. However, paradoxically, physicians in particular may only pay lip-service to the outwardly respectable discourse-scientific objectivity-where still they rely upon idiosyncratic, narrative-based decisions in everyday clinical judgment (Millenson 1999; Montgomery 2006; Groopman 2007). The very narratives that may offer insight into a patient's condition-those generated by the patients themselves-are overshadowed by a master narrative, again a dominant discourse, that of the medical narrative. Both are valuable, but one set of values becomes privileged (in this case, 'evidence' over 'anecdote').

Authors have a responsibility to remind readers of the values that permeate their work, or to position themselves in relation to other value complexes. Such critical reflexivity should inhabit curriculum development and studies. The curriculum reconceptualization movement (Pinar et al. 1995), now in a second wave of activity (Pinar 2006), treats the curriculum as a process rather than content (content is formally a syllabus), and as a structure of power and regulation. This body of work, sadly neglected in health professions education, reminds us that a curriculum can be treated as a 'text' - not just a set of words describing a course of study, but a process of activity unfolding through time, and reinventing itself. More, a curriculum can be 'read' as a variety of texts-functional, historical, economic, aesthetic, ethical, spiritual, gendered and political. Certain text positions have been privileged (an effect of power) - for example, it is common for managers to focus on the functional or instrumental text of the curriculum (timetabling), or cost implications (curriculum as economic text), at the expense of the curriculum as an ethical text (for example, should we still be using cadavers in teaching medical students; what level of intimacy is acceptable in an examination of a patient by a physiotherapy student; should nursing students report unacceptable behaviour by senior colleague teachers?)

As an example of curriculum as political text, we could ask why individualistic learning theory (including learning styles or learning related to personality) has been so dominant in health professions education curricula. First, where medicine has been privileged professionally in a hierarchy of health provision, then the medical model is a dominant discourse. Second, medicine itself has a tradition grounded in autonomy and heroic individualism (Ludmerer 1999). Further, this tradition is gendered male. It has resonance with the selfhelp and self-reliance, personality-driven, tradition that characterises the North American independent spirit of the frontiersman (Bellah et al. 2008). This also has deep resonance with the model famously described by the sociologist Max Weber describing the link 
between the Protestant Spirit and Capitalism, where the individual entrepreneur is guaranteed, through the Protestant Elect, a place in Heaven if he does not spend the profits from his business on self-indulgence, but ploughs such profit back in to the business (the spirit of capitalism). No wonder then that learning theories focusing upon the individual, and learning as privately owned capital, have readily taken root in medical education. These include learning approaches based on personality differences and individual cognition (connectionism), grounded in humanism and personal growth models. Importantly, such views are permeated by a value system that is itself taken for granted, transparent, rarely expressed as problematic and rarely brought to the foreground to be examined critically and reflexively. If we encourage structured feedback and deep reflection for our medical and health care learners, let us also apply these principles, as educators, to learning itself and the development of the curriculum.

What if you had grown up as a clinical educator in Russia after the 1917 Revolution? You would be right to think that you would be subject to a State-defined theory of learning, blatantly ideological - a dominant discourse and a curriculum as a political text. Here, the text is to do with an imperative of collectivism, social learning, co-ordination, co-operation and collaboration. The individual is not the unit of analysis. Rather, Lev Vygotsky, the founder of modern Russian learning theory (and by no means sympathetic with the ideals of the Communist Party) describes learning as a complex activity, first mediated through a community of others (social learning), and second, mediated through artifacts (material objects-for us the computer is now the most prominent).

Because of the Cold War, such collectivist learning theory did not reach most European and North American academic circles until the early 1970s, and then made little impact. But now there is a growing concern with embodied cognition, distributed cognition, communities of practice, actants (material objects acting as 'subjects', such as computers and measuring instruments), and cultural-historical activity theory. Indeed, for proponents of these social learning theories, it seems absurd that anyone could suggest that learning happens 'inside' individuals, is 'autonomous', or 'self directed'. Simply sitting and studying with a printed text already links you through an artifact to a culture and history, because any text is a product of context. Studying 'alone' with a computer is an oxymoron, especially if you are online. Thus, as we return to consider the tradition and place of individualistic learning theory in health professions education, we see that this too is ideologically driven, but has rarely attracted reflexive accounting or situating within a values system.

As we read, enjoy and learn from the varied selection of articles on curriculum interventions in this edition of the journal, let us then remember this bigger picture-that curriculum is a discourse, a series of texts, an effect of ideology, an expression of power and a producer of identity. Let us call for greater reflexivity in accounts of curriculum, that recognise values informing choices and methods, even where work is explicitly aimed at local or limited refinement of ideas, methods or practices, rather than reconceptualisation of a field.

Before we get judgmental about collectivism as an imperative, let us remember the paradoxical imperatives of a culture grounded in individualism, where 'Have a nice day!', and 'Enjoy!' are not invitations, but faintly disguised commands and demands. Democracy in education requires interplay between the individual and the collective through authentic dialogue-as the reconceptualists suggest, constructing curriculum as an extended and complicated conversation. 


\section{References}

Bellah, R. N., Madsen, R., Sullivan, W. M., Swidler, A., \& Tipton, S. M. (2008). Habits of the heart: Individualism and commitment in American life (3rd ed.). Berkeley: University of California Press.

Benbassatt, J., \& Baumal, R. (2009). A proposal for overcoming problems in teaching interviewing skills to medical students. Advances in Health Sciences Education, 14. doi:10.1007/s10459-007-9097-8.

Coulter, A. (2002). The autonomous patient: Ending paternalism in medical care. London: The Stationery Office.

Delany, C., \& Watkin, D. (2009). A study of critical reflection in health professional education: 'Learning where others are coming from'. Advances in Health Sciences Education, 14 . doi: 10.1007/s10459-008-9128-0.

Finlay, L., \& Gough, B. (2003). Reflexivity: A practical guide for researchers in health and social sciences. Oxford: Blackwell.

Foucault, M. (2005). The Hermeneutics of the subject: Lectures at the College de France 1981-82. New York: Picador.

Groopman, J. (2007). How doctors think. Boston: Houghton Mifflin.

Hasley, P. B., \& Arnold, R. M. (2009). Summative evaluation on the hospital wards. What do faculty say to learners? Advances in Health Sciences Education, 14. doi:10.1007/s10459-008-9127-1.

Hassed, C., de Lisle, S., Sullivan, G., \& Pier, C. (2009). Enhancing the health of medical students: Outcomes of an integrated mindfulness and lifestyle program. Advances in Health Sciences Education, 14. doi: 10.1007/s10459-008-9125-3.

Hsieh, H.-F., Wang, J.-J., Yen, M., \& Liu, T.-T. (2009). Educational support group in changing caregivers' psychological elder abuse behaviour toward caring for institutionalized elders. Advances in Health Sciences Education, 14. doi:10.1007/s10459-008-9122-6.

Kaiser, J. A., Dall'Alba, G., \& Livingstone, V. (2009). Impact of curriculum on understanding of professional practice: A longitudinal study of students commencing dental education. Advances in Health Sciences Education, 14. doi:10.1007/s10459-008-9114-6.

Kumagai, A. K., Murphy, E. A., \& Ross, P. T. (2009). Diabetes stories: Use of patient narratives of diabetes to teach patient-centred care. Advances in Health Sciences Education, 14 . doi: 10.1007/s10459-008-9123-5.

Ludmerer, K. M. (1999). Time to heal: American medical education from the turn of the century to the era of managed care. Oxford: Oxford University Press.

McKenna, L. G., Wray, N., \& McCall, L. (2009). Exploring continuous clinical placement for undergraduate students. Advances in Health Sciences Education, 14. doi:10.1007/s10459-008-9116-4.

Millenson, M. L. (1999). Demanding medical excellence: Doctors and accountability in the information age (2nd ed.). Chicago: The University of Chicago Press.

Montgomery, K. (2006). How doctors think: Clinical judgment and the practice of medicine. Oxford: Oxford University Press.

Pinar, W. F. (2006). The synoptic text today and other essays: Curriculum development after the reconceptualization. New York: Peter Lang.

Pinar, W. F., Reynolds, W. M., Slattery, P., \& Taubman, P. M. (1995). Understanding curriculum. New York: Peter Lang.

Sargeant, J. M., Mann, K. V., van der Vleuten, C. P., \& Metsemakers, J. F. (2009). Reflection: A link between receiving and using assessment feedback. Advances in Health Sciences Education, 14. doi: 10.1007/s10459-008-9124-4. 